\title{
THE IONIZATION OF GASES AT HIGH PRESSURES
}

\section{A Thesis}

Submitted to the Fralty of The Eraduate School of The University of Winnesota for the Degree of boctor of Filosophy

by

Henry A. Erikson, B. B. E.

Minneapolis, Minnesota

1908

Thesis Approved and Eecomended by

J. C. Nelennan, Professor of Physics, Universily of Toronto.

B. A. Bumstead, Professor of Physics, Yale Oniversity:

C. A. Skinner, Professor of Physics, University of Nebraska. 
-THE IONIZATION OF GASES-

AT HIGH PRESSURBS

The ionization produced in gases by the different ionizing rays has not heretofore been studied for pressures much greater than one atmosphere*. It is of considerable interest, however, to know how the ionization and the rate of recombination change as the density of the gas becomes considerable and approaches that of the liquid state.

In the experiments to be described the fonisation produced by the gamma $(y)$ rays of radiun was studied for pressures up to 400 atmospheres in the case of air, and up to the liquefying point in the case of carbon-dioxid.

The results obtained will be presented, after a description of the apparatus, under the following subdivisions:

Results for a1r;

1- Ionization current at different pressures and potentials,

2- The time required for the rays to produce the steady state,

3- The lingering of the ions,

4- The time required to collect the ions,

5- The 1onization current at different

${ }^{*}$ Phil. Mag. p.283, Vol. 3 (1902). 
temperatures.

Results for carbon-dioxid;

1- The lingering of the lons,

2- Ionization current at different pressures and potentials,

3- The natural conductivity of $\mathrm{CO}_{2}$ at different pressures and temperatures,

4- The ionization current at different temperatures.

Summary and Conclusions.

\section{-APPARATUS-}

A diagram of the apparatus used in the experiments is given in Fig.l.

$A$ is an iron cylinder 84 centimeters in length and 20.3 centimeters in diameter. Along the axis of the cylinder is a hole ( $S$ ) 5.1 centimeters in diameter, closed at each end by means of the two steel plugs ( $M$ and $N$ ) which have two threads to the centimeter and are made tight by means of lead packing.

The upper end of the hole (S) is lined with brass and serves as the ionization chamber, the inside dimensions of which are 16.7 centimeters in length and 4.9 centimeters in diameter. The electrodes are made of brass gauze 0.04 centimeter in thickness and are concentric cylinders separated on the average 


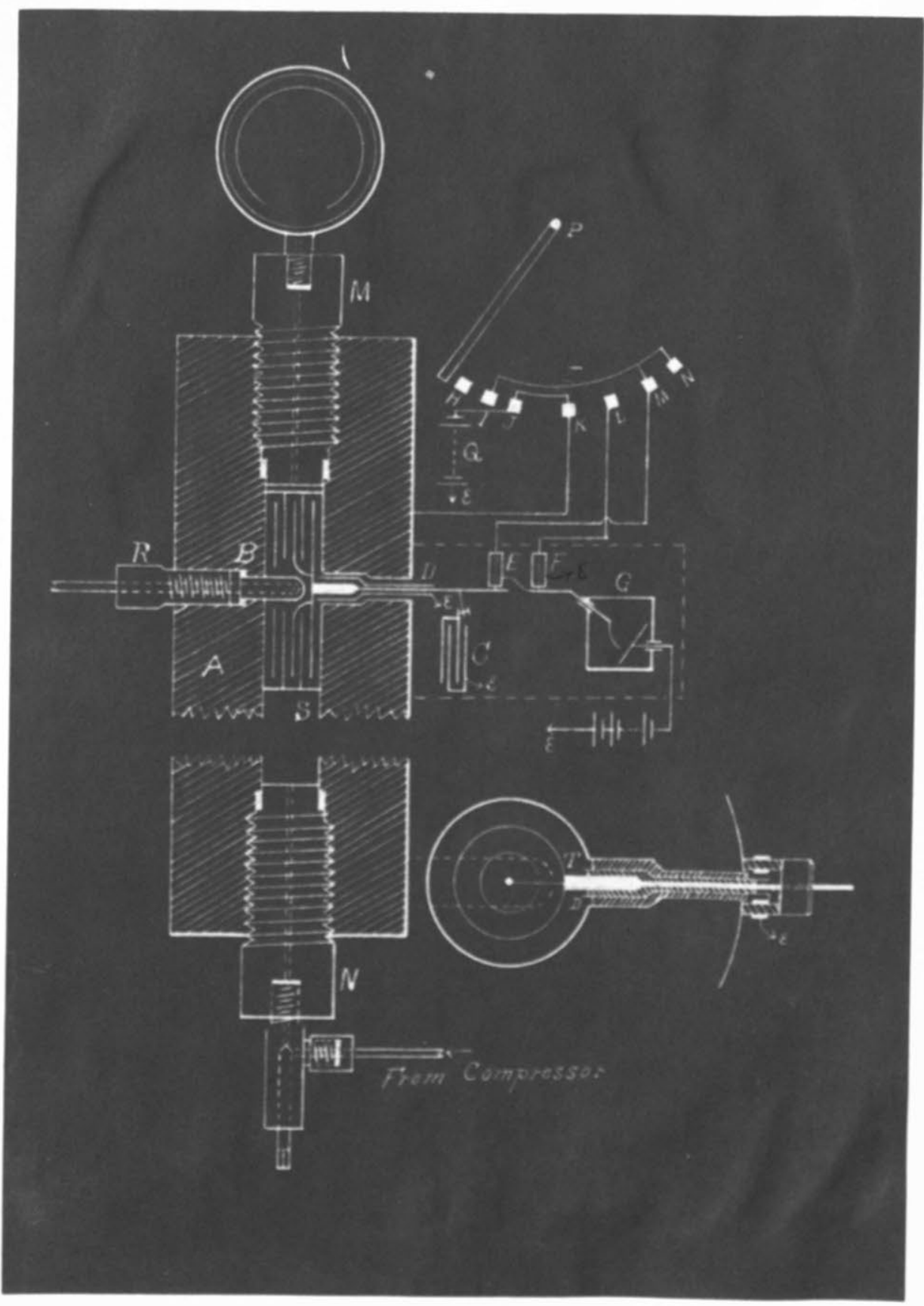

Fig.1. 
by 0.8 centimeter. The inner cylinder and the lining of the chamber form one electrode and are connected to the iron cylinder (A), while the other cylinder and the central wire form the other electrode $T$, and are insulated from A. The insulated electrode ( $T$ ) is supported by a brass rod passing through a hardrubber plug provided with a guard ring (D). This brass rod has a shoulder near the inner end and is threaded at the outer end, the nut on which serves to tighten the entire plug, the gas pressure alone on the inside not being sufficient to prevent leakage.

A brass thimble 0.22 centimeter in thickness projects into the ionization chamber at $B$. This thimble is set in lead packing and is held in place by the hollow, threaded, steel plug $(R)$ to which is at tached axially a slotted metal tube one meter in length.

A metal tube containing the radium salt can be placed inside the thimble and the penetrating gamma rays allowed to ionize the gas in the ionization chamber. The tube of radiun may be quickly withdrawn by releasing a stretched spiral spring attached to it. The insulated electrode $(T)$ is connected to two 
Me Lennan keys $(E)$ and $(F)$ and then to the leaf of a Wilson form of gold-leaf electroscope (a). C is a condenser of 0.001 microfarad eapacity and is used to increase the capacity of the electrode system, the purpose being to decrease the rate of motion of the leaf of the electroscope.

When the iron eylinder is given a potential different from that of the earth, a current begins to flow between the electrodes because of the fons produced in the gas by the gamma rays. If now the electrode $(T)$ is insulated from the earth by opening the key $\mathrm{F}$, the leaf of the electroscope begins to move and the time $(t)$ required for its image to pass a given number of divisions on the scale in the eyepiece of the microscope can be determined. Knowing the capacity $C^{\prime}$ of the electrodes and the potential (v) necessary to deflect the leaf the given number of divisions, the absolute value of the current may be determined from the relation

$$
I=\frac{C^{1} V}{t} .
$$

In order to determine the number of ions present in the gas at any instant it is necessary to make a number of consecutive connections. This is accom- 
plished by means of the pendulum $P$. The arrangement is such that as the pendulum reaches $H$ it shuts off the rays by releasing the spring which vithdraws the radium from the cylinder, at I it opens the key $E$, at $J$ it connects the cylinder to the battery $Q$, at $K$ it disconnects the battery and connects the cylinder to earth, at I 1t insulates the leaf of the electroscope, at M it connects the electrode to the electroscope and at $\mathbb{N}$ it opens again the key $\mathbb{E}$.

The electroscope was found much more convenient than the quadrant electrometer in this investigation, as the inappreciable inertia of the leaf permits an observation to be repeated very quickly and easily.

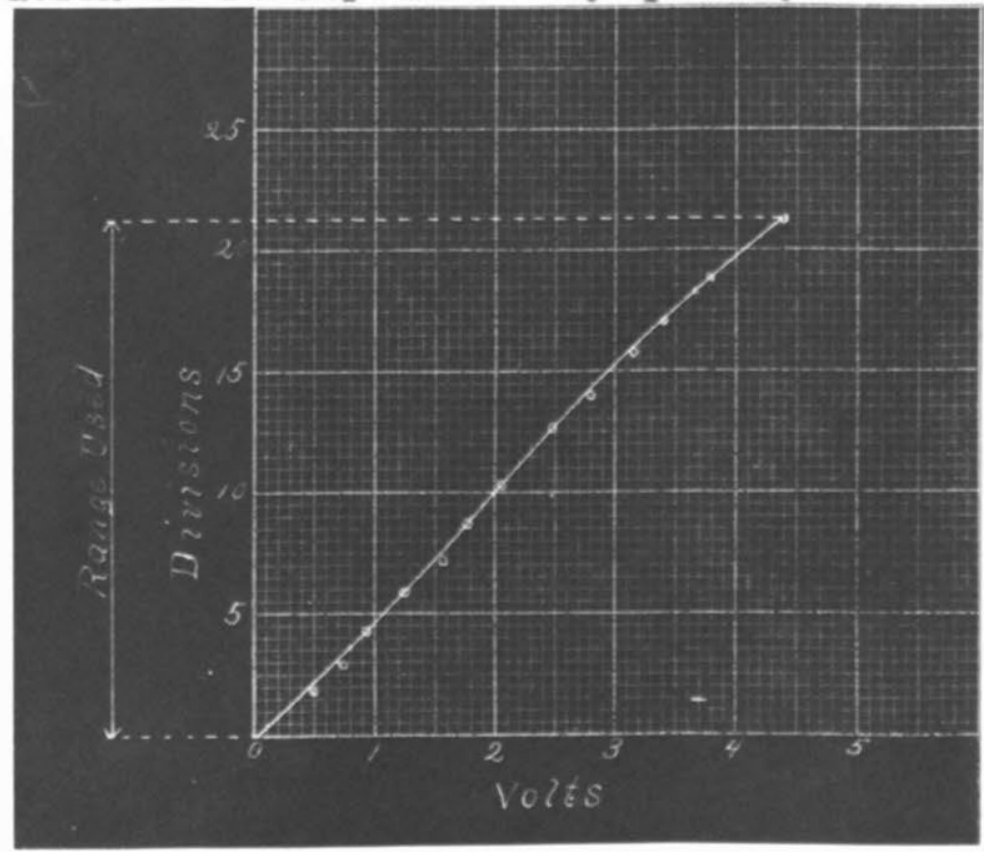


Fig.2 gives the calibration ourve for the electroscope and shows the range used in the current readings. The same sensibility was used throughout the entire investigation, the sensibility selected being determined by the size of the available capacity (c), the strength of the currents involved and the magnitude of the charge present in the gas at any instant. The potential on the plate of the electroscope was obtained from a battery of fifty large lead chloride cells. The potentials of the cylinder up to one thousand volts were obtained from a high potential storage battery and potentials higher than one thousand volts were obtained by means of a small static machine in conjunction with a large battery of Leyden jars.

The radioactive substance used was about 0.6 gratn of a salt containing $1 \%$ of radium bromide.

\section{-RESULTS FOR AIR-}

In the case of a1r, pregsures up to two hundred. atmospheres were obtained by means of a thitehead compressor belonging to a liquid air plant and pressures higher than two hundred atmospheres were obtained 
by means of a Cailletet hand compressor, the liquid used in it being parafein-oil. The air used was purifled by passing through lime before entering the compressor and then after being compressed it was passed through a cylinder containing caustic potash. In part of the work the air was also passed through a quantity of cotton just before entering the ionization chamber in order to remove any dust that might be present.

The Ionization current at Different Pressures and Potentials.

1. The relation between the eurrent and the voltage was obtained for a large number of pressures. The various voltages were applied to the cylinder and thus to the electrode connected to it, and the time was taken which was required for the leaf of the electroscope to move a number of divisions equal to the range shown in Fig.2. The current in any case is proportional to the reciprocal of this time.

To illustrate the nature of the readings a few results are given in Table $I$. 


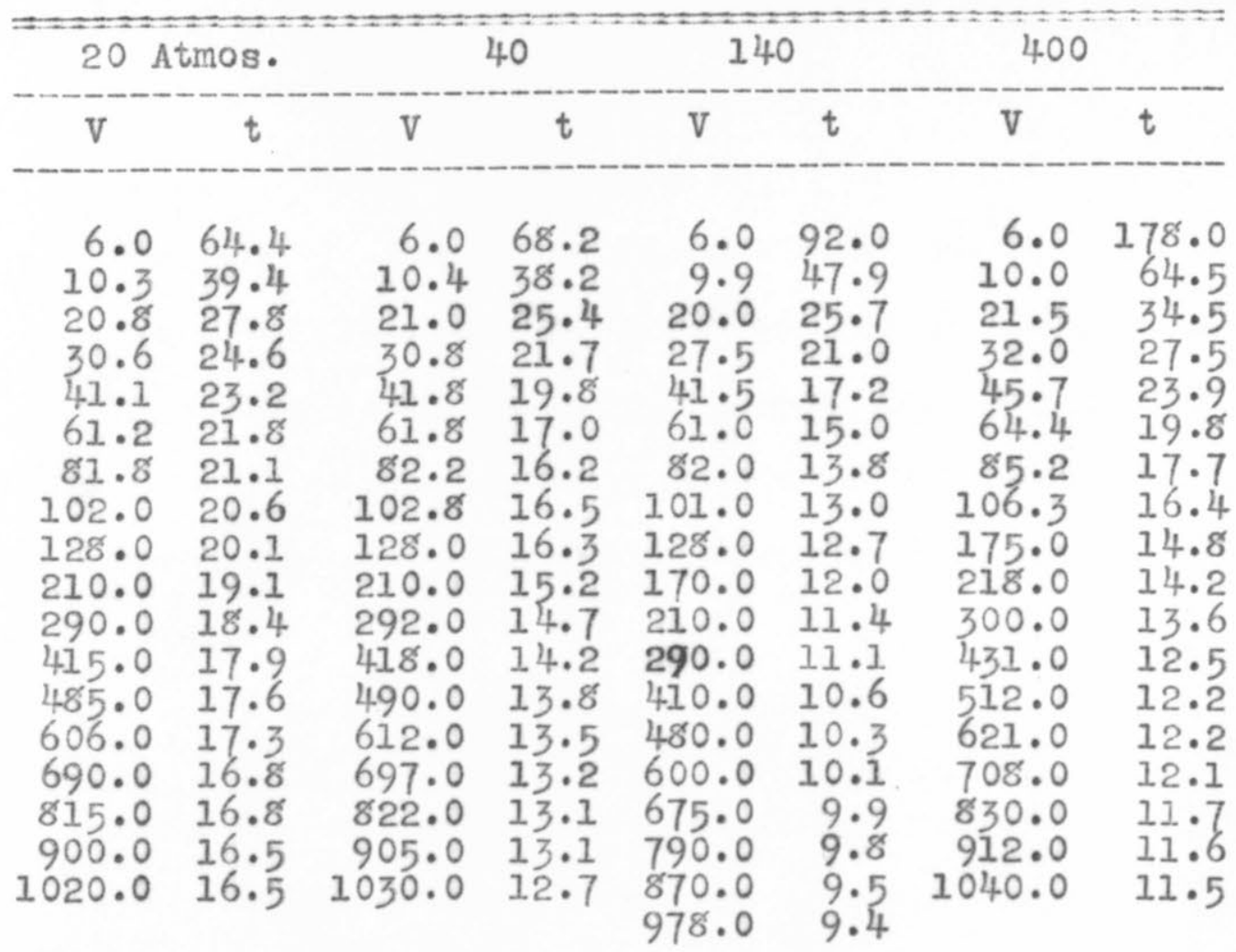

\section{Table I.}

The results are shown graphically in Fig.3, where the abscissas represent the voltage and the ordinates the reciprocal of the time. The pressure corresponding to each curve is also given. 


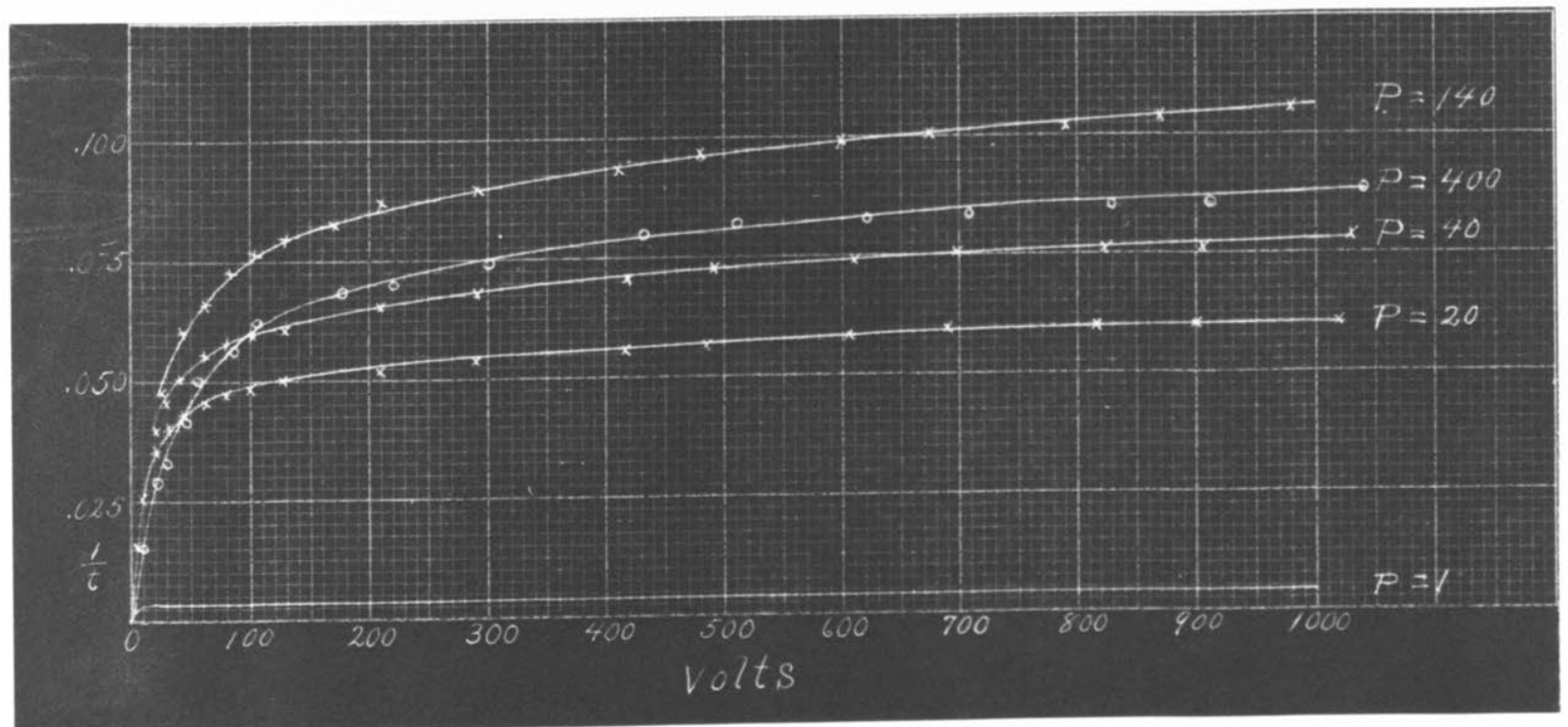

Fig. 3 .

It is noticed that the curves take the general form of the saturation curve at the pressure of one atmosphere, only that at the higher pressures, after the first rapid increase of the current, they still rise considerably with increase of voltage. In comparing with the curve for one atmosphere, it is seen that at the higher pressures the currents are considerably larger though not proportional to the pressure since at 20 atmospheres the current with 1000 volts is only about 15 times that at one atmosphere. By doubling the pressure to 40 atmospheres the current increases but $30 \%$, and at 140 atmospheres with a pressure seven times that at 20 the current is but 
1.8 timos as 1 arge as at 20 . Finaliy, at 400 atmonphores the ourrant in 1 ess than that at 1 ho and not muoh above that at 40 . W1th a 10 w voltage the ourront at 400 atmosphoros 18 eeon to be oven mallas than that at 20 .

Some rosults which show the relation of the ourrents at different presures then enell voltagos are applied to the eleotrodos aro raproeanted by the ourves in $71 \mathrm{~g} \cdot 4$.

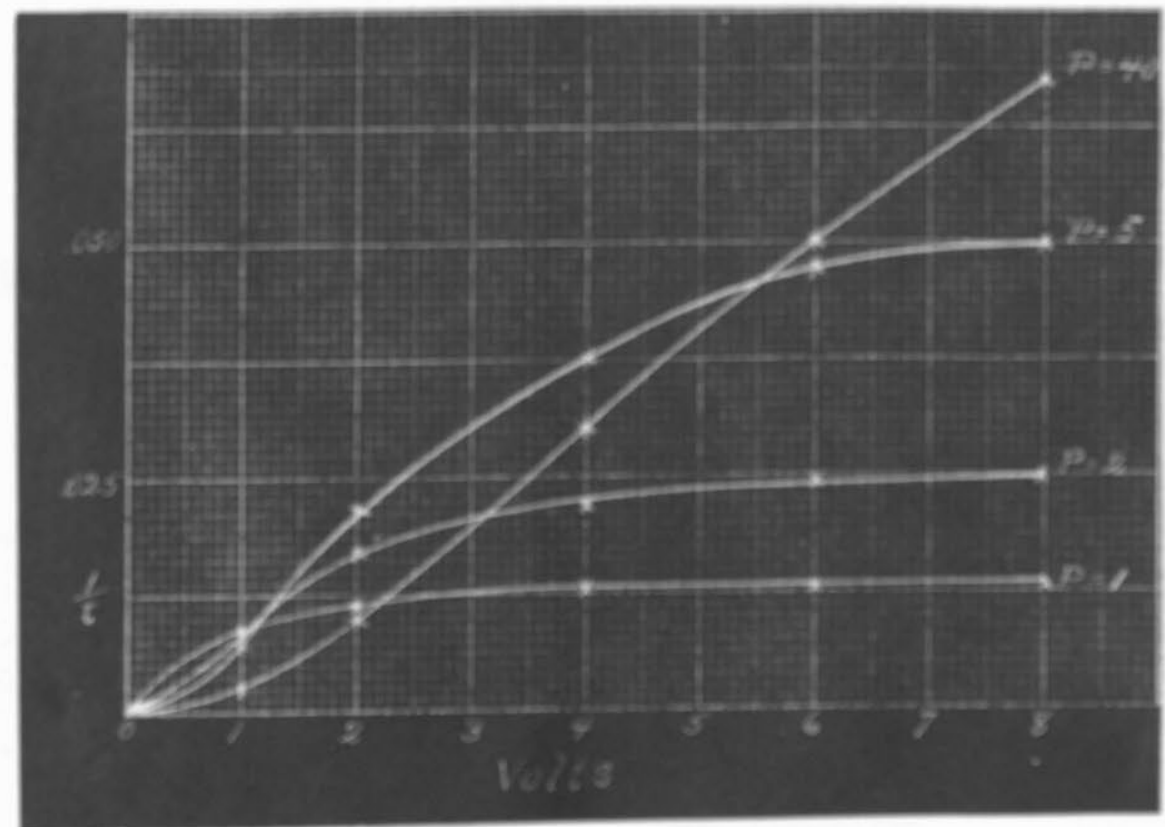

$$
71 \mathrm{~g} \cdot 4 .
$$

As the prossure incroases the initial slopo of the

curvas 1a lass. They soon Mao howaver and up to 140 atmo spheres intersect the oarliar ourvos. 
Inasmuch as the current thru the gas does not increase regularly with the density of the gas, it is of interest to plot results showing how the current varies with the pressure of the gas when the difference of potential between the electrodes is maintained at a constant value. Table II. gives some results of this kind which were obtained for a number of potentials ranging from 8.3 to 2500 volts. The initial pressure in each case was 400 atmospheres and readings were taken as the pressure was reduced by steps. The results given for the time in Table II. represent the average of from three to eight separate times obtained in seconds by means of a stop watch. The potential of the plate of the electroscope was adjusted so that the gold leaf was at zero. The watch was started the instant the key $F$ was opened and when the leaf came to the end of the range used the watch was stopped. The following is a characteristic set and was obtained for $P=240$ and $V=1050$;

$$
9.6,9.7,9.6,9.4 .
$$

The current is proportional to the reciprocal of this time. Whenever a redetermination was made the results checked to well within $2 \%$ even tho the cylinder had, in the meantime, 


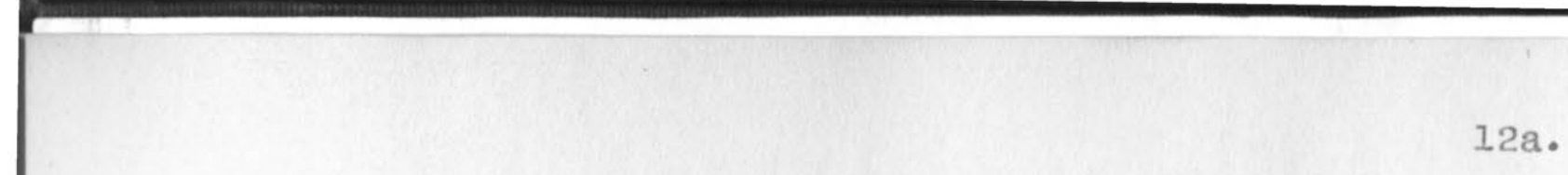

b eən anptied of air and then again refilled. Likewise a similar agrement was found to exist when the currentvoltage eurves $\left(1 . \theta_{.}\right.$, curves like those shown in $\mathrm{Fig.3}$ ) wəre obtained for any pressure. 


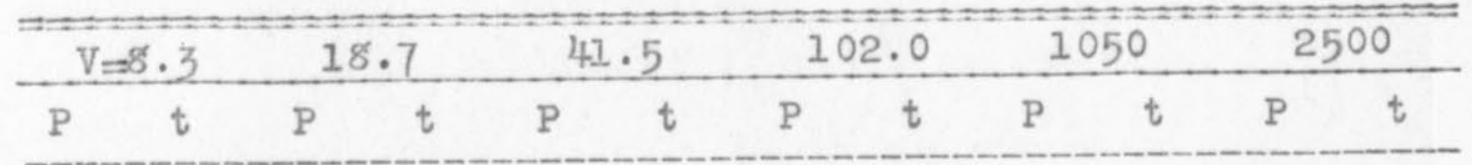

$\begin{array}{llll}400 & 86.2 & 401 & 41.7\end{array}$ $\begin{array}{llll}390 & 83.7 & 390 & 39.0\end{array}$ $\begin{array}{llll}380 & 82.5 & 380 & 38.8\end{array}$ $\begin{array}{llll}370 & 83.7 & 370 & 38.1\end{array}$ $36181 \cdot 3$ 35080.0 34078.7 33178.1 32178.7 31177.5 30175.0 29075.0 28273.7 27175.0 26171.2 25170.0 $24067 \cdot 5$ 23066.2 22065.0 21065.0 20162.5 19061.2 18062.5 17060.0 16057.5 $150 \quad 57.5$ 14056.2 12755.0 11753.7 11052.5 10051.2 9050.0

7948.7

$\begin{array}{lll}68 & 48.7\end{array}$

$58 \quad 45.0$

$50 \quad 45.0$

3946.2

$\begin{array}{lll}30 & 43.7\end{array}$ 1743.7

\section{$350 \quad 36.4$}

34036.2

33035.8

31034.8

30034.1

29133.7

28233.3

27133.1

26132.4

25131.7

24031.1

23030.5

22030.1

21030.0

20029.2

19028.7

18028.1

$\begin{array}{lll}170 & 27 \cdot 5\end{array}$

$15927 \cdot 0$

15026.6

14025.9

13025.8

12025.5

11025.0

10024.7

8724.7

8023.9

6824.1

6024.3

$5024 \cdot 5$

4025.0

$3025 \cdot 9$

$\begin{array}{ll}30 & 25 \cdot 9 \\ 20 & 27.7\end{array}$
321.33 .2 $\begin{array}{lllll}400 & 24.1 & 400 & 17.0\end{array}$

$\begin{array}{llll}390 & 23.4 & 291 & 16.8\end{array}$

38223.4

37023.0

36022.9

35022.7

34122.1

33121.1

32021.3

31021.2

30020.8

29020.4

28020.3

27019.9

26019.9

25019.3

24019.0

23018.8

22018.7

21018.5

20018.3

19018.1

$\begin{array}{lll}180 & 17.7\end{array}$

17017.4

16017.4

15017.2

14017.2

13016.8

12016.8

11016.7

10016.8

9016.6

8016.7

7017.0

6017.4

5018.1

3819.1

3020.3

2022.3
38016.5

37016.5

36116.0

35116.0

34215.8

33215.5

32115.2

31015.1

30115.0

29014.7

28114.7

27114.4

26014.2

25014.0

24013.8

23013.7

22013.5

21013.4

20013.4

19313.2

18013.1

$170 \quad 12.7$

16012.8

14912.6

13912.7

13012.6

11912.6

11012.8

9912.9

8913.1

7813.2

7113.5

5914.6

5014.6

3916.0

2818.0

1920.2
$400 \quad 11.6 \quad 400 \quad 10.4$ 39111.4

$38011.4 \quad 38010.1$

37011.1

$\begin{array}{llll}360 & 11.1 & 361 & 9.7\end{array}$

35111.0

34010.7

33010.6

32110.6

31010.4

30110.2

28910.1

28010.0

$270 \quad 9.9$

$261 \quad 9.7$

$250 \quad 9.6$

2409.6

$230 \quad 9.6$

$320 \quad 9.3$

$210 \quad 9.3$

2009.3

1919.2

1819.2

1709.1

1609.0

1499.0

1409.1

1309.1

1209.1

$110 \quad 9.2$

$100 \quad 9.4$

$90 \quad 9.4$

809.8

6910.0

5710.8

5011.1

$40 \quad 12.4$

2614.5

3419.4

$322 \quad 9.1$

3019.1

$284 \quad 8.8$

2628.8

2498.4

$230 \quad 8.2$

217.8 .2

2017.9

$184 \quad 7.9$

$170 \quad 7.7$

$\begin{array}{ll}152 & 7.7\end{array}$

$137 \quad 7.8$

1207.9

$98 \quad 8.2$

$80 \quad 8.6$

609.4

3810.8

2016.0

2015.0

Table II. 
The results given in Table II. are shown graphically in $\mathrm{Fig} \cdot 5$.

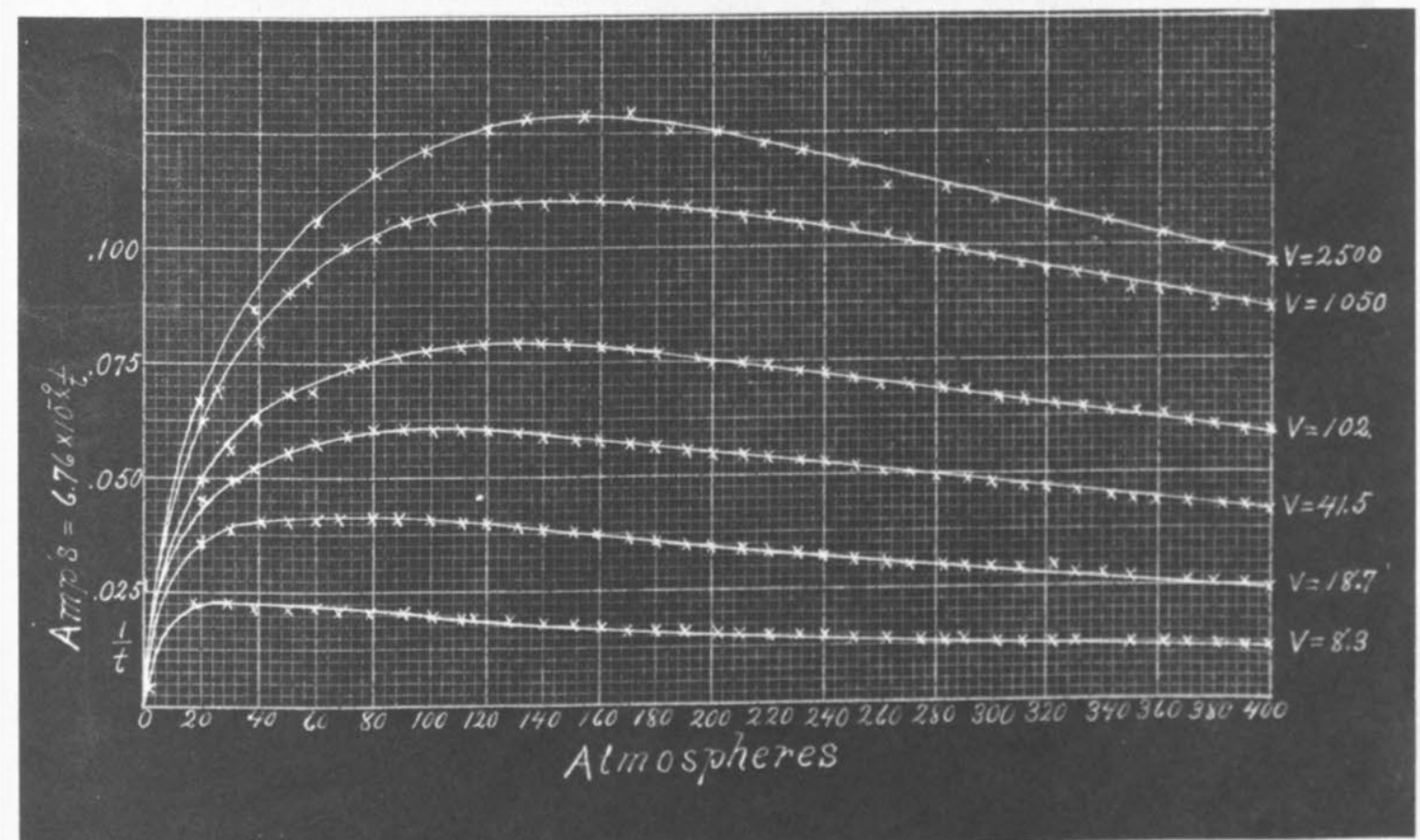

F18.5.

As the density of the gas begins to increase there $1 \mathrm{~s}$, as was seen before, a marked increase in the number of Ions produced by the rays. The number drawn to the electrodes is not, hovever, proportional to the density for, as the density increases, it becomes more and more diffloult to collect the ions, so that the current obtained becomes a maximum at a point depending upon the 
density of the gas and the potential between the electrodes. For 1050 volts the maximum is at about 150 atmospheres. With the higher potentials, for all pressures somewhat higher than those giving the maximum current, the curves are straight lines; that is, the current is an inverse linear Punction of the density. At the higher potentials

The difficulty with which the ions are collected is undoubtedly due, in a large measure at least, to an initial recombination; that is, the return of a newly

electron
formed for to its parent atom, the existence of which was suggested by Rutherford (Radioactivity, p.33) and by Bragg and Kleeman (Phil. llag., Vol.11, p.466, 1906). As the difficulty with which the lons are collected increases with the density the nearness of the molecules must play an important part in this initial recombination. Since, as will be seen later, the natural recombination of the ions decreases as the density increases, it is quite probable that the currents show in Fig.5 for the potentials 1050 and 2500 include all of the free lons produced by the rays and that the difference between 
the two curves is due mainly the aid of the field due to the potential between the electrodes, would return to their parent atom.

\section{The Time Required for the Rays
to Produce a steady state.}

2. When the rays begin to act upon a gas at high pressure it takes an appreciable time before the number of ions in the gas reaches a steady value, the rate of production being greater than the rate of recombination until the steady state is attained. The greater the pressure the longer is the time required. Results 1llustrating this, for pressures of 200 and 400 atmospheres, are given in FIg. 6 where the ordinates are proportional to the number of lons collected after the rays have acted upon the gas an interval represented in seconds by the abscissas, the difference of potential used being 1000 volts. 


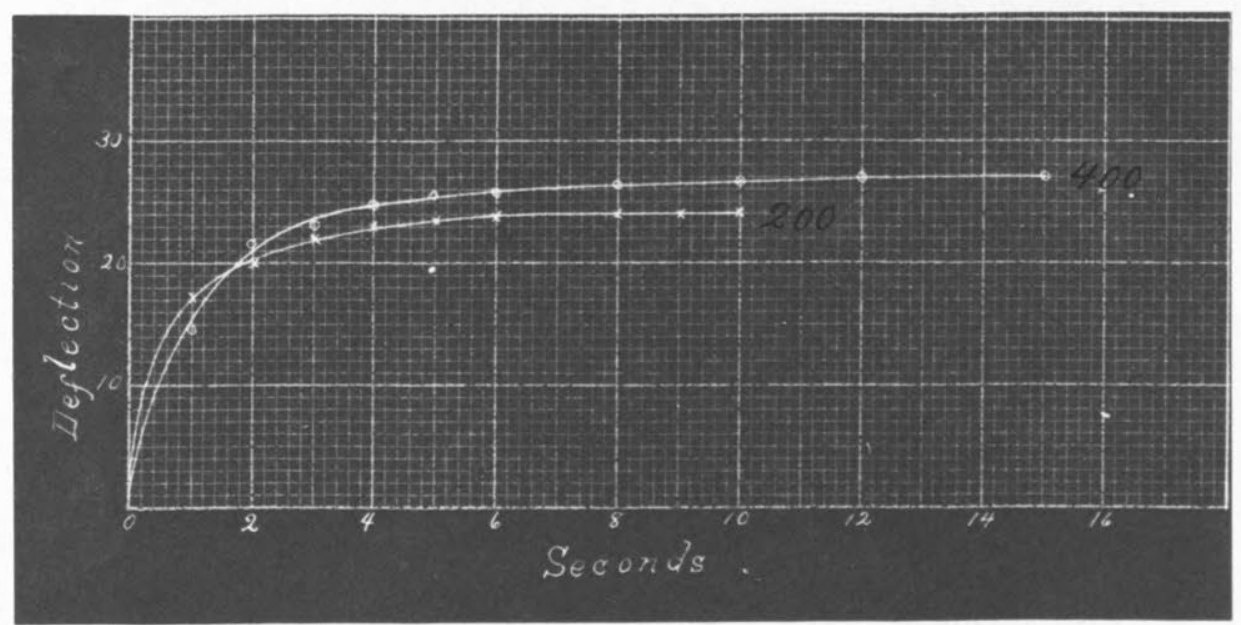

Fig.6.

It will be seen that at 200 atmospheres it takes about eight seconds before the ions in the gas reach a maximum number, whereas at 400 atmospheres it requires about fourtean seconds.

\section{The Lingering of the Ions.}

3. As the density of the gas increases the readifree

ness with which the, ions recombine diminishes to a marked extent, so that some of the lons linger for some time before they recombine. The results of some experiments on this point are show in Fig.7. 


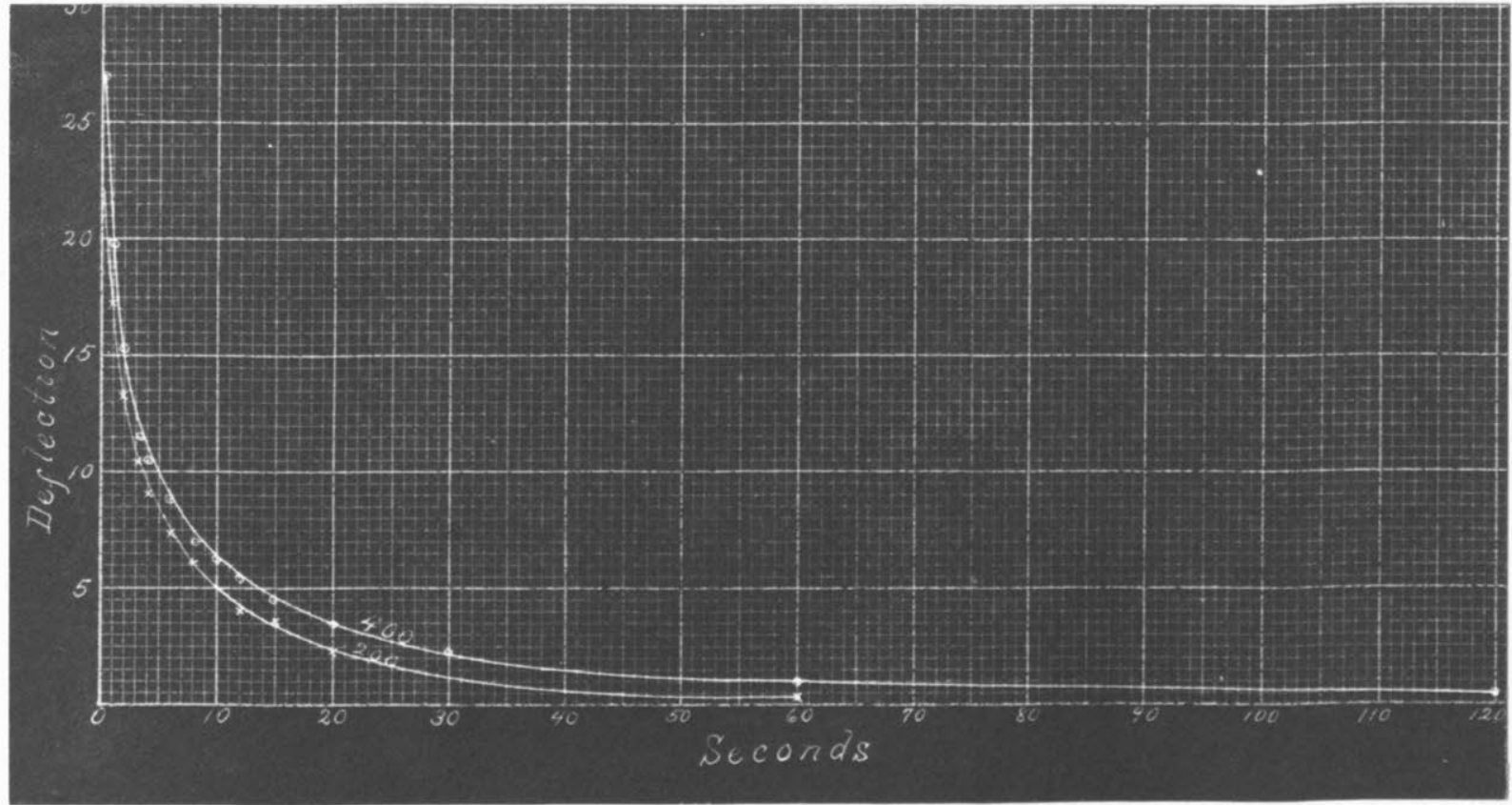

Fig.7.

The gas was exposed to the rays for a length of time sufpicient to produce the maximum number of ions. The rays were then discontinued and after a measured interval of time, 1000 volts were applied to the electrodes and the deflection of the leaf due to the charge acquired by the electrodes was measured. The deflection in this case is proportional to the charge and 18 ropresented by the ordinates in Fig.7, the time interval being represented in seconds by the abscissas. The 
pressures used were 200 and 400 atmospheres. It will be seen that at 200 atmospheres an appreciable number of ions are still uncombined sixty seconds arter the rays were discontinued and that at 400 atmospheres there $\operatorname{are}$ still uncombined ions at the end of 120 seconds. The lingering of the lons is further 1llustrated by the results given in Fig., ,

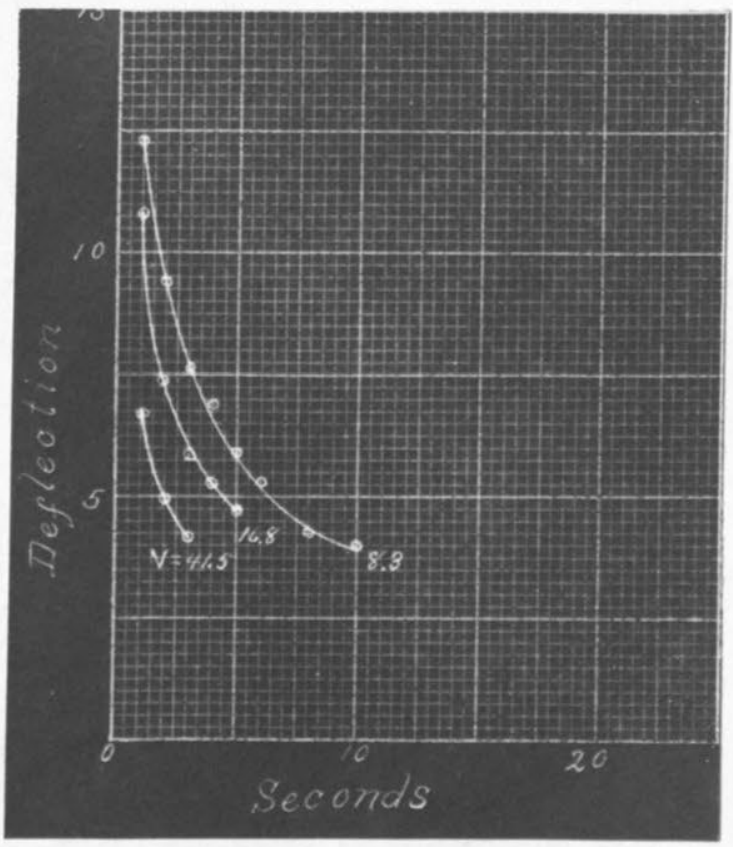

Fig. 8 .

Where the ordinates are proportional to the number of Ions obtained at 195 atmospheres with a potential of 
1090 volts, after the rays had ceased to act upon the gas for a time represented in seconds by the abscissas, the electrodes during this whole interval having the difference of potential given at the end of the curves. Thus even with a constant difference of potential of 41.5 volts acting, there are still an appreciable number of lons present after three seconds from the time the rays ceased to act.

\section{The Time Required to Collect the Ions.}

4. The slowness with which the ions are drawn to the electrodes is shown by the curve in Fig.9, which gives the time required for the voltage to collect the ions after the rays have ceased to act, the pressure being 200 atmospheres, the potential 1000 volts and the distance between the electrodes $8 \mathrm{~m} \cdot \mathrm{m}$. 
21.

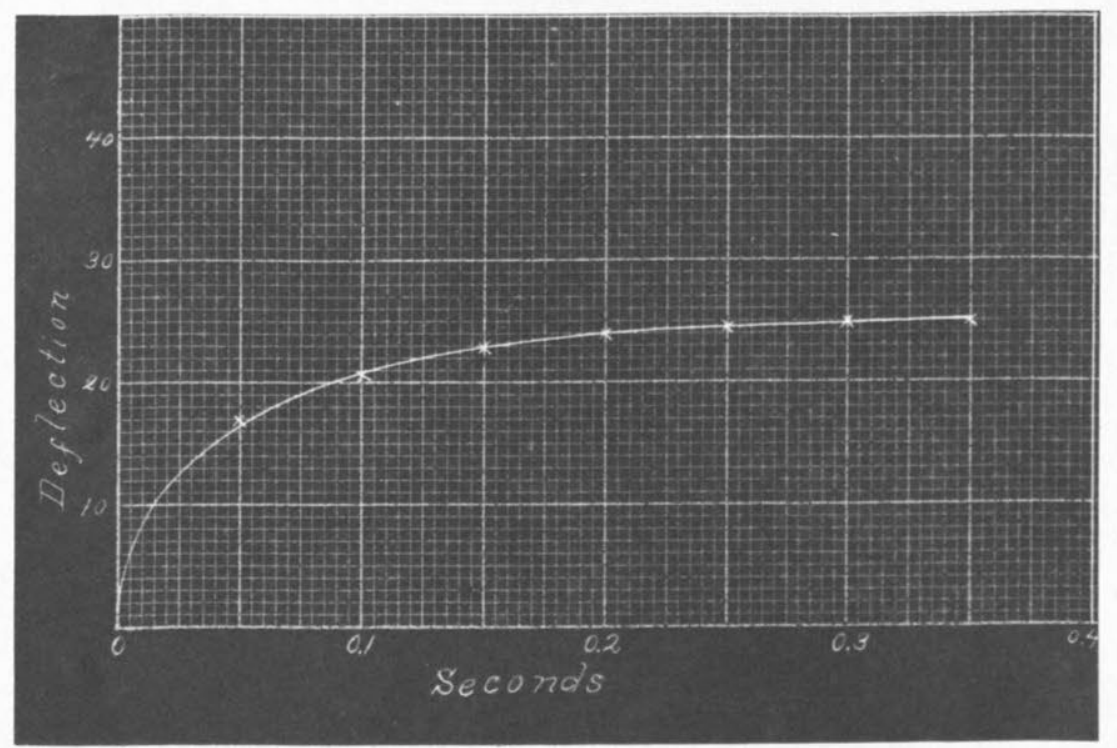

Fig.9.

It is seen that in this case it requires three-tenths

of a second for all of the lons to get to the electrodes under a potential gradient of 1250 volts to the centimeter.

The Ionization current at Different Temperatures.

5. An increase in the temperature of the air at high pressures causes a marked change in the 1onization current, and in the number of lons collected when the rays have ceased to act and a voltage is applied to the electrodes. 


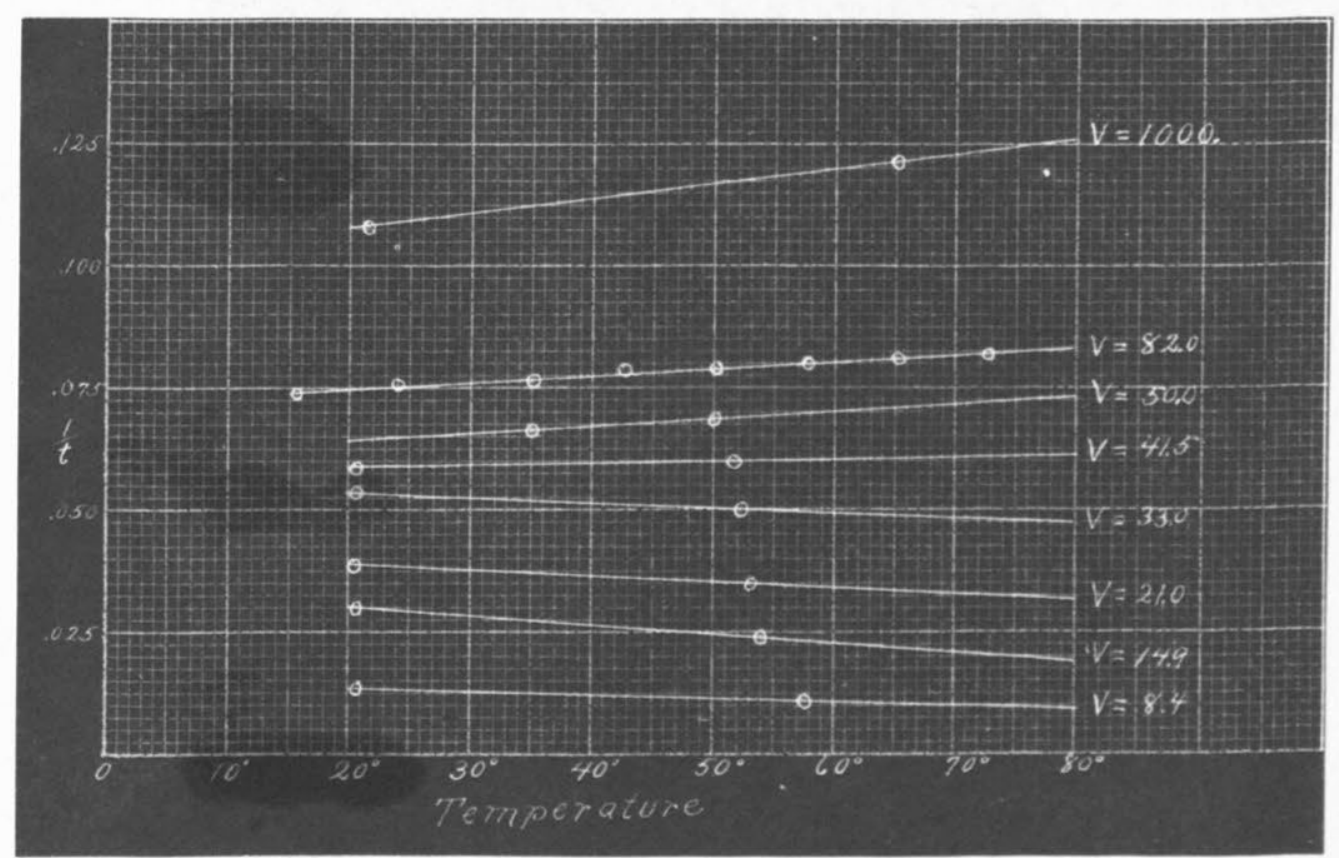

Fig. 10.

In Fig.10 the ordinates of the curves shown are proportional to currents obtained at the various temperatures represented by the abscissas when the constant voltages given in each case were applied to the electrodes, the density of the gas being kept constant, the pressure at $20^{\circ}$ being 200 atmospheres. With a difference of potential of about 38 volts there was 
no change in the current as the temperature of the gas increased. With potentials greater than 38 volts the current increased with the temperature, and with potentials less than 38 volts, the current decreased. The amount of the change in the current per degree was greater the greater the difference between 38 volts and. the potential appliod.

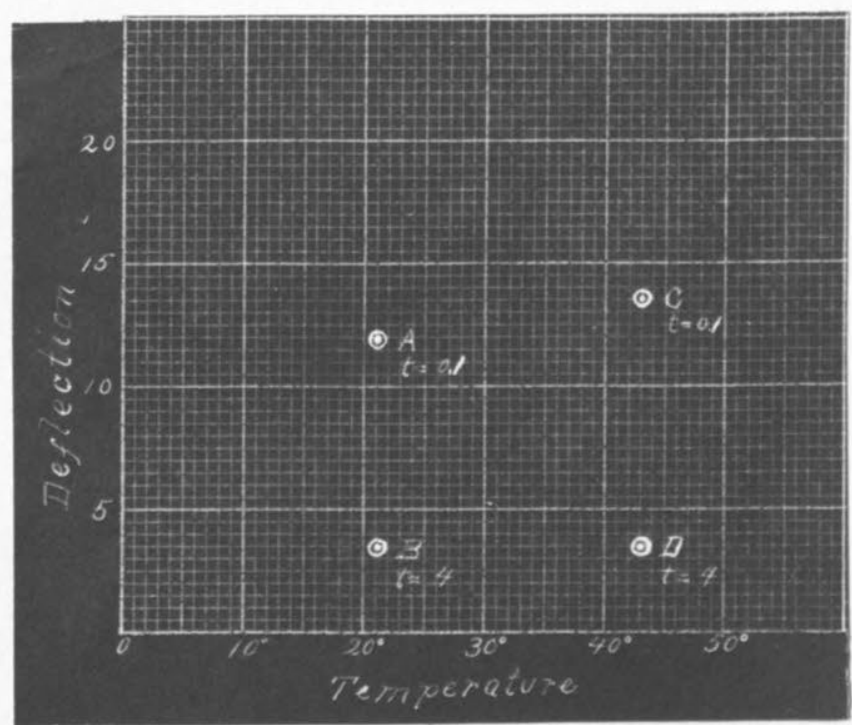

Fig.11.

The change in the number of $10 \mathrm{~ns}$ that are arawn to the electrodes at two different temperatures is shown in Fig.11. The ordinate represented by A is proportional to the number of lons drawn to the electrodes when a 
difference of potential of 1000 volts was applied, onetenth of a second after the rays ceased to act, the temperature bəing $2 I^{\circ}$ Centigrade and the pressure of the gas 200 atmospheres. B is proportional to the number obtained four seconds after the rays ceased to act, the temperature and pressure being the same as for A. C and. D are corresponding points at a tempsrature of $43^{\circ}$, the density of the gas boing the sane as for $A$ and $B$. It is seen that more ions are drawn to the electrodes one-tenth of a second after the rays cəased to act, at the higher temperature than at the lower. Aft $\rightarrow$ an interval of four seconds, however, the number is in this case the sane at both tamperatures.

This indicates that at the higher temperature a greater number of freg lons are produced by the rays, and also that there is at the higher temperature a greater loss by natural recombination, as was shown by Mc Clung to bo the case at densitios of a lower value.

The two last above mentioned changes are opposite in their effect on the ionization current and it seens reasonable to suppose that the potential for which there is no change in the current with temporature, establishos a condition such that the increase in the number of frev ions is just offset by the loss due to the increase of 
the rate of recombination. At potentials lers than this the time required for the lons to pass to the electrodes is greater and therefore there is a greater loss by recombination and a consequent decrease in the current. At higher potentials, however, the time is shorter so that there is a smaller loss dus to recombination and therefore an increase in the current.

The indications are, however, that at 38 volts the cument remains constant only for a short range of temperature and that the ourve soon begins to turn downard indicating an incroase in the change por degres of the rate of recombination. This will bo brought out in a subsøquent paper.

I have as yot made no deternination of the change with terperature of the ionic velocity due to the fiold. A change of this kind would have no effect at the higher potentials whore all the lons aro dram to the electrodes so that there is no rocombination. At lower potentials it would effect somewhat the slopo of the currenttemperature curves. The general character of the ourves shown in Fig.10 is, however, independent of a change of this kind. 
The results given below were obtained with commercial carbon dioxid, for pressures up to the liquid state. The method employed for fllling the ionization chamber with carbon dioxid was as follows: The supply oylinder containing the liquid $\mathrm{CO}_{2}$ was inverted and placed higher than the testing cylinder. It was allowed to ramain in this position for some time, so as to permit any free light impurities to rise to the top of the I1quid and any heavy impurity to sink to the bottam. Before fllling the lonization chamer the liquid was allowed to escape into the air for a time sufficient to force out any heavy impurity which might have collected near the outlet at the bottom of the cylinder.

The Lingering of the Ions in Carbon-Dioxid-

1. The results for the lingering of the fons in carbon-dioxid at 61 atmospheres pressure and at a temperature of $21^{\circ} \mathrm{C}$. are shown in $\mathrm{Fig.12}$. 
27.

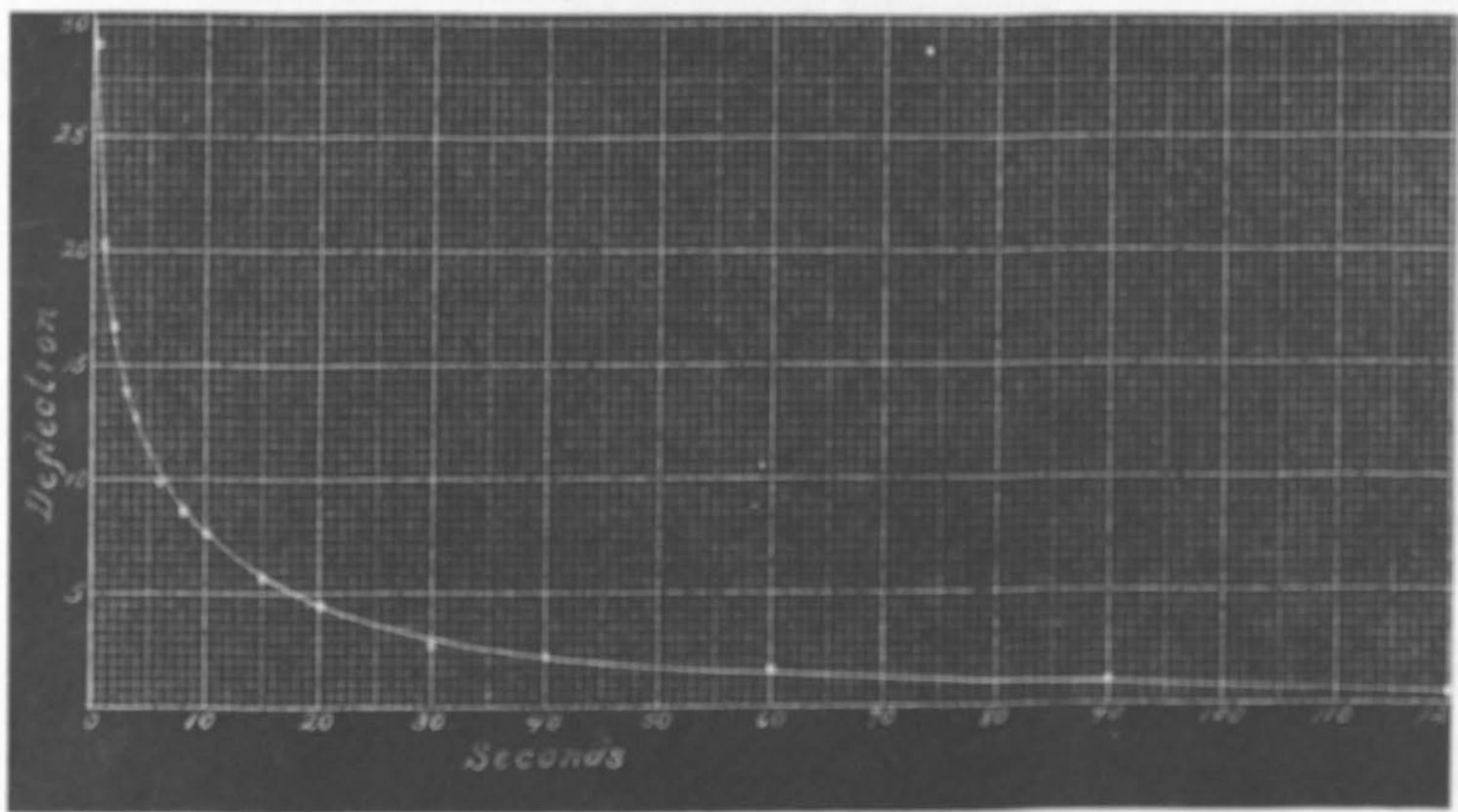

71g.12.

Here again the ordinates are proportional to the number of 1ons present, at times after the rays had oeaeod to aot which are oxprossed in seoonds by the corresponding abso1ssas. The 11ngortng is hero much moro markod than in a1r at the aase presaure, doubtiess orring to the groater density, the anount baing comparable to that for air at 400 atmospheres.

The Ion1sation curront at Difforant Prosouras and Potentials.

2. The relation betwoan the prossure and the current 
due to the lons produced by the gamma rays was determined for a number of potentials. The results obtained for the time $(t)$ at the various potentials and pressures are given in Table III. At the higher pressures there is an appreciable natural conductivity in the gas. This in 1tself gives rise to a current which is present when the rays are acting. The time for the current due to the rays alone was calculated by taking the product of the time due to the natural current alone and of the time for the two currents together and dividing this by the difference of the two times.

\begin{tabular}{|c|c|c|c|c|c|c|c|c|c|}
\hline P & $t$ & $\underline{P}$ & $t$ & P & t & $\therefore P$ & $\underline{t}$ & $P$ & t \\
\hline $\begin{array}{l}6 \\
10 \\
15 \\
20 \\
25 \\
30 \\
35 \\
40 \\
45 \\
50 \\
55 \\
60 \\
64\end{array}$ & $\begin{array}{l}5.56 \\
56.52 \\
55.0 \\
57.3 \\
58.7 \\
64.5 \\
62.7 \\
68.1 \\
70.5 \\
84.6 \\
91.0\end{array}$ & $\begin{array}{l}6 \\
10 \\
15 \\
20 \\
25 \\
30 \\
35 \\
40 \\
45 \\
50 \\
55 \\
60 \\
64\end{array}$ & $\begin{array}{l}41.2 \\
34 \cdot 7 \\
31 \cdot 1 \\
28 \cdot 1 \\
27.6 \\
26.8 \\
26.9 \\
27 \cdot 1 \\
26.8 \\
27 \cdot 7 \\
28.5 \\
31.9 \\
33 \cdot 3\end{array}$ & $\begin{array}{r}6 \\
10 \\
15 \\
20 \\
25 \\
30 \\
35 \\
40 \\
45 \\
50 \\
55 \\
60 \\
64\end{array}$ & $\begin{array}{l}35.52 \\
29.0 \\
25.9 \\
22.0 \\
20.7 \\
19.7 \\
19.7 \\
19.0 \\
18.6 \\
18.7 \\
18.7 \\
19.7 \\
20.6\end{array}$ & $\begin{array}{l}6 \\
10 \\
15 \\
20 \\
25 \\
30 \\
35 \\
40 \\
45 \\
50 \\
55 \\
60 \\
64\end{array}$ & $\begin{array}{l}32.6 \\
26.2 \\
22.4 \\
19.0 \\
17.7 \\
16.1 \\
15.6 \\
14.6 \\
14.1 \\
14.3 \\
13.8 \\
13.5 \\
13.7\end{array}$ & $\begin{array}{l}6 \\
10 \\
15 \\
20 \\
25 \\
30 \\
35 \\
40 \\
45 \\
50 \\
55 \\
60 \\
64\end{array}$ & $\begin{array}{r}27.5 \\
21.3 \\
17.2 \\
15.8 \\
12.5 \\
12.9 \\
12.2 \\
11.4 \\
10.8 \\
10.7 \\
9.9 \\
9.3 \\
9.2\end{array}$ \\
\hline
\end{tabular}


These results are shown graphically in Fig.13, where the ordinates are proportional to the currents and the abscissas represent pressures up to 65 atmospheres.

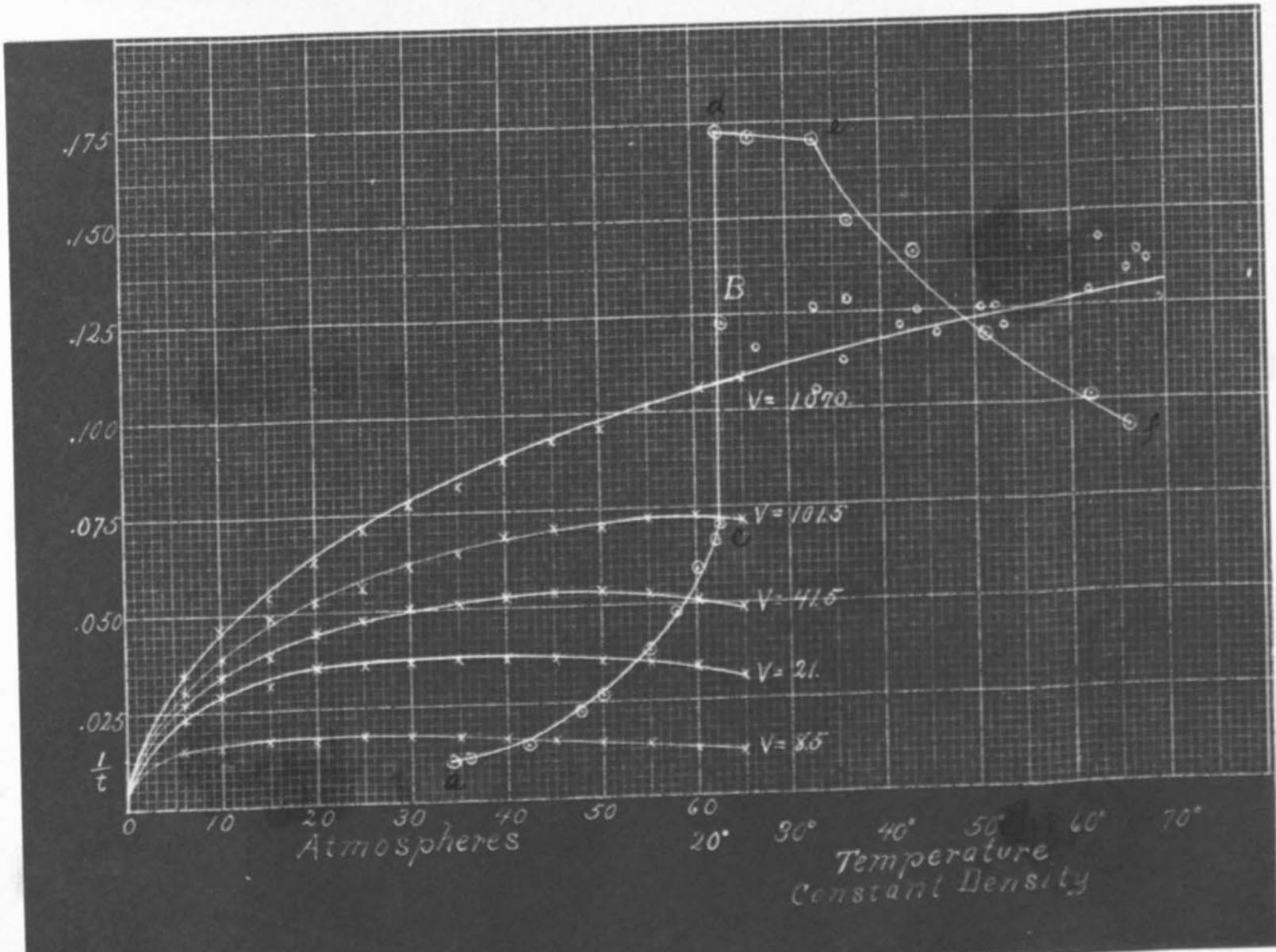

Fig.13.

Up to the pressure at which the gas liquelies the curves are in general similar to those for air. This indicates that the ionization is independent in a large neasure at 
least of the intermolecular forces present, even when the gas approaches the liquid state.

The Natural Conductivity of Carbon Dioxid.

3. In Fig.13 the curve B represents the current due to the natural conductivity of the $\mathrm{CO}_{2}$, the differenoe of potential being 1000 volts. The first portion of the curve from a to $c$ shows how the natural conductivity increases as the gas approaches the liquid state. There is a very sudden increase (od) in the conductivity at 62.5 atmospheres which is the pressure at which the $\mathrm{CO}_{2}$ liqueries for the temperature involved; namely, $22.6^{\circ} \mathrm{d}$. At this stage when the cylinder had become fliled with the liquid the lower valve was closed so that the density could not change. Heat was then applied to the outside of the cylinder and readings for the current were taken as the temperature slowly increased. The results are shown by the portion "def" of curve B, where now the absoissas represent temperatures instead of pressures and where the ordinates are proportional to the current due to the natural conductivity. It is seen that the conductivity 
increases slowly with the rise in temperature up to about $33^{\circ} \mathrm{C.}$, above which however it diminishes rapidly.

The Ionization current at Different Temperatures.

4. The Ionization current due to the rays was also obtained in this range of temperature, the density remaining constant. It undergoes no marked change as 18 shown by the extended portion of the ourrent pressure ourve at 1070 volts, the eurrent increasing slowly with the rise in temperature. The fluctuating of the readings was due to inacouracy in measuring the short time interval (about two seconds) required for the leaf of the electroscope to move through the range used, the available capacity being too small. This shows that the ionization due to the rays is, at least for the sensibility and potential involved in this investigation, quite independent of the natural dissociation to which the liquid or vapor conductivity is due.

\section{-SUAGCARY AND CONCLUSIONS-}

The results obtained in this investigation and the conclusions dram from them are as follows: 
(a)- $\mathrm{As}$ the denstty of air or $\mathrm{CO}_{2}$ increases, the ionization current attains a maximu value. The higher the potential the greater is the value of the density giving the maximum current. At potentials higher than 100 volts the current, beyond the maximum point, is an inverse linear function of the density. A probable explanation of these results is that when the molecules are closer together it becomes more difficult for an ion to leave its parent atom.

(b) The veloolty of the iono, wden a givan pow tontial gradient, if less the groator the donsity ints

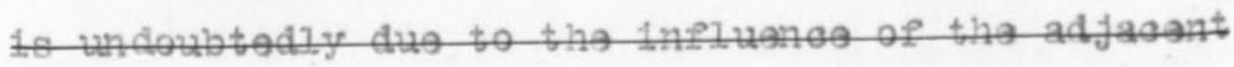
molooulos.

(b) - It requires several. seconds at the higher densities for the rays to produce a steady state, indicating that a proportionately maller number of free fons are produced.

(a)- When the density of a gas inareases the ions inger for a longer time before they recombine, showing that after an lon becomes free it is more difficult for it to combine with another ion when the dansity of the 
gas is considerable.

(d)- The rate of recombination of the ions increases as the temperature of the gas increases.

(e)- The number of free 1ons produced by the rays increases with the temperature.

(f) - The natural conductivity of $\mathrm{CO}_{2}$ gas increases as the gas approaches the liquefying pressure. When the gas liquefies its conductivity suddenly changes to more than double its forner value. (g)- The natural conductivity of liquid $\mathrm{CO}_{2}$ decreases slowly w1th increasing temperature up to about the oritical temperature when 1 t beg1ns to decrease rapidly.

(h) - The 1onization produced by the rays is quite Independent of the changes $\mathrm{CO}_{2}$ undergoes when 1t 11quefies and when it passes thru the oritical temperature and pressure. 
In conclusion I wish to express my sincere thanks to Dr. John Zeleny for many helpful suggestions and to Dean F. S. Jones for kindly securing for mo the necessary apparatus . 
Biographical Sketch.

Henry Anton Frikson was born July 30, I869, in lit. Horris, Waushara co. Wisconsin. He prepared for the university at Willmar Seminary and at the vorther $\boldsymbol{n}$ Indiana liounal. He entered the University of limesota at the beginning of the school year I893-4 and graduated. fron the course in electrical engineering at the close of the year I895-6. After graduating he taught one year in the High School of Rochester, Minnesota and then returned to the university of llinnesota as instructor of physics, which position he held until I905 when he wes macle assistent professor of physics in the same department.

Preparatory to the receiving of the Doctors Degree he presents as a minor a two years study or Differential and. Integral calculus as presented by Todhunter and Differential equations as presented by $\%$. $\pi$. Johnson, all takon under the instruction of Dean H. T. Bdà. As a second minor he presents a two years study of the Theory of Blectricity and Jagnetism as presented by 
Arthur Gorden Webster, the work being pursued under the direction of Dean Jacy.

As a major he presents two lines of study, one in experimental physics and the other in theoretical physics and astronorny.

In experimental physics he presents a two years study of contact potential and surface layers, and a two years study of the ionization of sases and liquids, all pursued under the direction of $\mathrm{Dr}$. John Zeleny.

In theoretical phys ies an astronomy he offers the pollowing as studies pursued in class:

Least squares.

Practical Astronomy (Trensit work)

oppolzer's Bahn b estimmuns.

Ro $v$ th's Risid Dynamies.

Nobster's Dynamios.

ligner's Kinetic Theory of Gases.

Lectures on Wolecular Physios taken at the

University of chicago.

Pupins Wave Propagation. 
Drudés: Optics.

The time equivalent of the above major and minors

is fourteen and one half years. 